\title{
Cysteine proteinase inhibitors in human and rat male sex glands
}

\author{
K. Minakata*, M. Asano*, S. Isemura $\dagger$ and N. Harada $\ddagger$ \\ * Department of Legal Medicine Hamamatsu University, School of Medicine, 3600 Handa, \\ Hamamatsu 431-31; †Department of Oral Biochemistry, Nitgata Faculty, Nippon Dental \\ University, Niigata 951; and $\ddagger$ Shizuoka Women's College, 3-2-3, Nunohashi, Hamamatsu 432, \\ Japan
}

\begin{abstract}
Summary. The testis and prostate of men had two types of cysteine proteinase inhibitors of different isoelectric point ( $\mathrm{pI}=4.5$ and 6.3$)$ and molecular masses $(90000$ and 12000 ). The seminal vesicle contained not only these two inhibitors but also a basic inhibitor with a $\mathrm{pI}=9.5$ and $M_{\mathrm{r}} 11000$. In rats, the inhibitors in the testis and prostate consisted of two types with pI values of 4.3 and 4.8 and $M_{\mathrm{r}} 90000$ for both. In addition to these two inhibitors, the seminal vesicle contained large amounts of two basic inhibitors with pI values of 7.5 and 8.3 and $M_{\mathrm{r}}$ of 11000 for both. We suggest that the basic cysteine proteinase inhibitor found in semen might be excreted from or be modified in the seminal vesicle.
\end{abstract}

\section{Introduction}

Cysteine proteinase inhibitors are present in human semen in much higher concentrations than trypsin inhibitors which are known to prevent fertilization in vitro (Stambaugh et al., 1969) and in vivo (Zaneveld et al., 1970). Cysteine proteinase inhibitors in semen consist of two types In-A and In-B (Barrett et al., 1984; Minakata \& Asano, 1985) with isoelectric points $4 \cdot 7-5.0$ and 9.5 and molecular masses of 16000 and 11000 , respectively. It is not known whether the two types of inhibitors are excreted from different glands or this heterogeneity is induced by some modification of an original substance. We have therefore investigated these inhibitors in testis, seminal vesicle and prostate.

Vitamin E deficiency is known to cause sterility (Mattill \& Conklin, 1920; Evans \& Bishop, 1922; Sure, 1923-24). In vitamin E-deficient rats, the content of cysteine proteinase inhibitor was 5 -fold that of the normal value in testis but similar to the normal value in the seminal vesicle (unpublished data). Therefore, the characterization of the inhibitors in rat testis, prostate and seminal vesicle was also investigated.

\section{Materials and Methods}

Ficin, papain, bromelain, trypsin, $N \alpha$-benzoyl-DL-arginine-2-naphthylamide (BANA) and $N \alpha$-benzoyl-DL-arginine4-nitroanilide (BAPA) were purchased from Sigma, St Louis, MO, U.S.A. Ferritin, aldolase, bovine serum albumin, ovalbumin, chymotrypsinogen, cytochrome $c$. Sephadex G-100, Sephadex IEF were from Pharmacia, Uppsala, Sweden; carrier ampholytes were from LKB. Bromma, Sweden and Na-(trans-3-carboxy-2-oxiranylcarboxy)- $N$-(4guanidinobutyl)-L-leucinamide (E-64) was from Protein Research Foundation, Osaka, Japan. Cathepsins B and H were partly purified from rat liver by the method of Davidson \& Poole (1975).

Human male sex glands were obtained from 6 cadavers subjected to autopsy in the Department of Legal Medicine within $15 \mathrm{~h}$ after death. The cadavers were aged from 19 to 45 years, and $10 \mathrm{~g}$ of each sex gland were used. Contamination by blood was thought to be very small, because the content of trypsin inhibitor in sex glands is only $20 \%$ of that of the cysteine proteinase inhibitor, whereas the former was 10 times higher than the latter in serum. 
Male sex glands were obtained from Wistar strain rats weighing about $340 \mathrm{~g}$ and the glands of 6 rats were gathered and examined.

Tissues were homogenized in a Polytron homogenizer with four volumes of cold distilled water. The homogenate was centrifuged at $15000 \mathrm{~g}$ for $20 \mathrm{~min}$ and precipitate was discarded. The volume of the supernatant was adjusted to $50 \mathrm{ml}$ with distilled water.

Inhihitor assay. BANA was used for the assay of cathepsins B and H, ficin, bromelain and trypsin by the method of Barrett (1972). BAPA was used for the assay of ficin, papain and trypsin. Because the available cysteine proteinases were not completely purified ones, the amount of active enzymes was determined by titrating them with E-64, a low molecular mass cysteine proteinase inhibitor, by the method of Tamai et al. (1981). To each of the solutions containing the inhibitor $(0.02-0.2 \mathrm{mi}), 0.15 \mathrm{nmol}$ of each enzyme was added and the mixtures were preincubated for 10 min at room temperature. Then the substrate solution was admixed and the remaining enzymic activity was measured by reading absorbance at $530 \mathrm{~nm}$ after $30 \mathrm{~min}$ incubation at $37^{\circ} \mathrm{C}$ (Barrett, 1972). Then the inhibitory power was calculated by the ratio of absorbance at $530 \mathrm{~nm}$ of the sample solution to that of the control solution without the inhibitor (Minakata \& Asano, 1985).

Isoelectric point determination. The supernatant of the tissue homogenate $(50 \mathrm{ml})$ was dialysed against $1 \%$ glycine solution for $18 \mathrm{~h}$ and mixed with $5 \mathrm{~g}$ Sephadex IEF and $2 \mathrm{ml}$ ampholytes $\mathrm{pH} 3 \cdot 5-10$. The mixed gel was poured into a flat vessel to apply the voltage between both sides of the vessel for $18 \mathrm{~h}$. The proteins in the homogenate were arranged in the gel according to the respective isoelectric points. To find focussed zones of the inhibitors, the gel bed was sectioned into 32 fractions with a fractionating grid. Each section was eluted with $5 \mathrm{ml}$ cold distilled water to extract the inhibitor, and the $\mathrm{pH}$ of the eluate was measured. Then the $\mathrm{pH}$ of all eluted fractions was adjusted to $\mathrm{pH} 6.5$ with $3 \mathrm{ml}$ potassium phosphate buffers of different $\mathrm{pH}$ values. The fractions containing the inhibitor were used for molecular mass determination.

Molecular mass determination. A Sephadex G-100 gel column $(2 \cdot 2 \times 52 \mathrm{~cm})$ was eluted with $0.03 \mathrm{M}-$ potassium phosphate buffer $\mathrm{pH} 6.5$ containing $0.15 \mathrm{M}-\mathrm{NaCl}$, and was calibrated with ferritin, aldolase, bovine serum albumin, ovalbumin, chymotrypsinogen and cytochrome $c$ as standards.

\section{Results}

\section{Human}

When the cysteine proteinases were added to the homogenates of three kinds of male sex glands, all three homogenates inhibited them in the order of cathepsin $\mathrm{H}$, cathepsin $\mathrm{B}$, ficin, papain and did not inhibit bromelain. Using ficin as the standard enzyme, the mean \pm s.d. inhibitor content for the 6 cadavers was $2 \pm 0.4 \mathrm{nmol} / \mathrm{g}$ testis, seminal vesicle or prostate. The inhibitor content in semen for 83 persons was $3 \pm 0.6 \mathrm{nmol} / \mathrm{ml}$ (Minakata \& Asano, 1985). The inhibitory power of the homogenates against trypsin was weaker than the inhibitory power against papain. Appreciable amounts of hydrolysing activity of the BANA or BAPA substrates were not observed in the mixture of the substrates and the same amount of homogenate as used for the measurement of inhibitors. This means that the levels of cysteine proteinase inhibitors were much higher than the levels of active cysteine proteinases in the 3 tissues.

The results of the analysis of the isoelectric focussing in a granulated gel were as follows. The sample from testis or prostate exhibited two inhibition peaks as shown in Fig. 1(a). The peaks of $\mathrm{pI}=4.5$ and $\mathrm{pI}=6.3$ were denoted as $\mathrm{Hi}-1$ and $\mathrm{Hi}-2$, respectively. $\mathrm{Hi}-1$ inhibited both ficin and cathepsin $\mathrm{H}$ equally, whereas $\mathrm{Hi}-2$ inhibited cathepsin $\mathrm{H}$ specifically but ficin only weakly. In addition to these two peaks, the sample from seminal vesicle showed a third peak at $\mathrm{pI}=9 \cdot 5$, denoted as Hi-3 in Fig. 1(b), which inhibited cathepsin $\mathrm{H}$ specifically but ficin only weakly.

The molecular masses of $\mathrm{Hi}-1, \mathrm{Hi}-2$ and $\mathrm{Hi}-3$ were 90000,12000 and 11000 , respectively, determined by Sephadex G-100 gel filtration method as the average values of 3 replicates. The gel filtration patterns of the homogenate of testis without electrofocussing showed an inhibition peak at $M_{\mathrm{r}} 90000$, corresponding to $\mathrm{Hi}-1$ and the other peak at $M_{\mathrm{r}} 12000$, corresponding to $\mathrm{Hi}-2$. Therefore, the electrofocussing had no effects on the molecular masses of the inhibitors. Figure 1 indicates that trypsin inhibitory power was weaker than ficin inhibitory power in human male sex glands.

The preliminary immunological characteristics were examined by double immunodiffusion with 


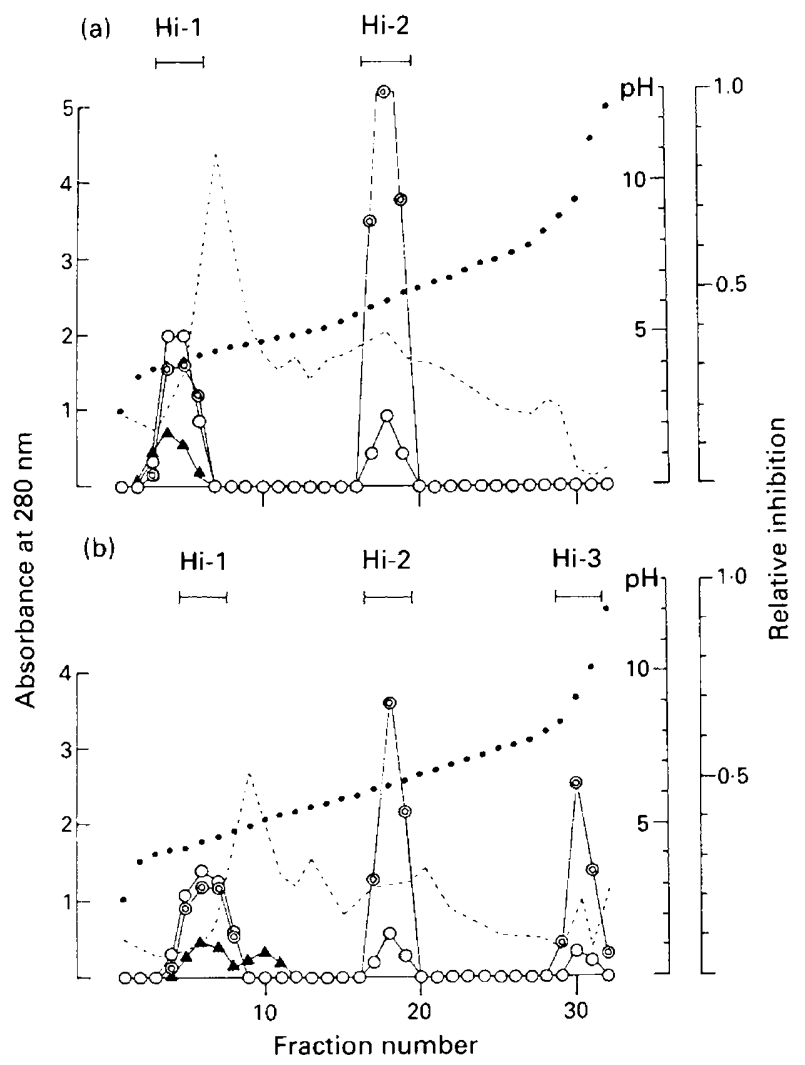

Fig. 1. Electrofocussing of proteinase inhibitors in (a) testicular tissue and (b) seminal vesicle tissue of men. The inhibitory activities of $0.15 \mathrm{ml}$ eluates were tested against $0.15 \mathrm{nmol}$ ficin $(\mathrm{O}-\mathrm{O})$, cathepsin $\mathrm{H}(\odot-\bigcirc)$ and trypsin $(\boldsymbol{\Delta}-\mathbf{\Delta})$. Synthetic substrate such as BANA or BAPA was used for the assay. $\mathrm{pH}$ value; --- u.v. absorbance of the eluate.

anti-human cystatin S (Cys-S) antibody (Minakata \& Asano, 1984; Isemura et al., 1984a). Figure 2 shows that precipitin lines formed between the antibody and Cys-S in saliva, In-A in semen and $\mathrm{Hi}-1$ in seminal vesicle, respectively. Their precipitin lines fused without spur formation, indicating identical antigenicities. On the other hand, human serum did not react with anti-Cys-S antibody (Isemura et al., 1984b).

Rat

Taking ficin as the standard enzyme, the inhibitor content was $1 \pm 0.2 \mathrm{nmol} / \mathrm{g}$ for testis or prostate and $4 \pm 1 \mathrm{nmol} / \mathrm{g}$ for seminal vesicle. No appreciable amounts of hydrolysing activities were detected in the mixture of the BANA or BAPA substrates and the homogenate of testis or seminal vesicle, but the homogenate of prostate contained large amounts of trypsin-type enzymes.

The homogenate of testis or prostate showed two inhibition peaks in electrofocussing as shown in Fig. 3(a). The peaks at $\mathrm{pI}=4.3$ and $\mathrm{pI}=4.8$ were denoted as $\mathrm{Ri}-1$ and $\mathrm{Ri}-2$, respectively and they inhibited ficin and cathepsin $\mathrm{H}$ equally. In the seminal vesicle, the peaks $\mathrm{Ri}-1$ and $\mathrm{Ri}-2$ were very small while two new peaks, $\mathrm{Ri}-3$ at $\mathrm{pI}=7 \cdot 5$ and $\mathrm{Ri}-4$ at $\mathrm{pI}=8 \cdot 0$, were dominant (Fig. $3 b$ ). Both Ri-3 and Ri-4 inhibited cathepsin $\mathrm{H}$ specifically but ficin only weakly. Figure 3 indicates that the trypsin inhibitory power was comparable to ficin inhibitory power in rat male sex glands. The 


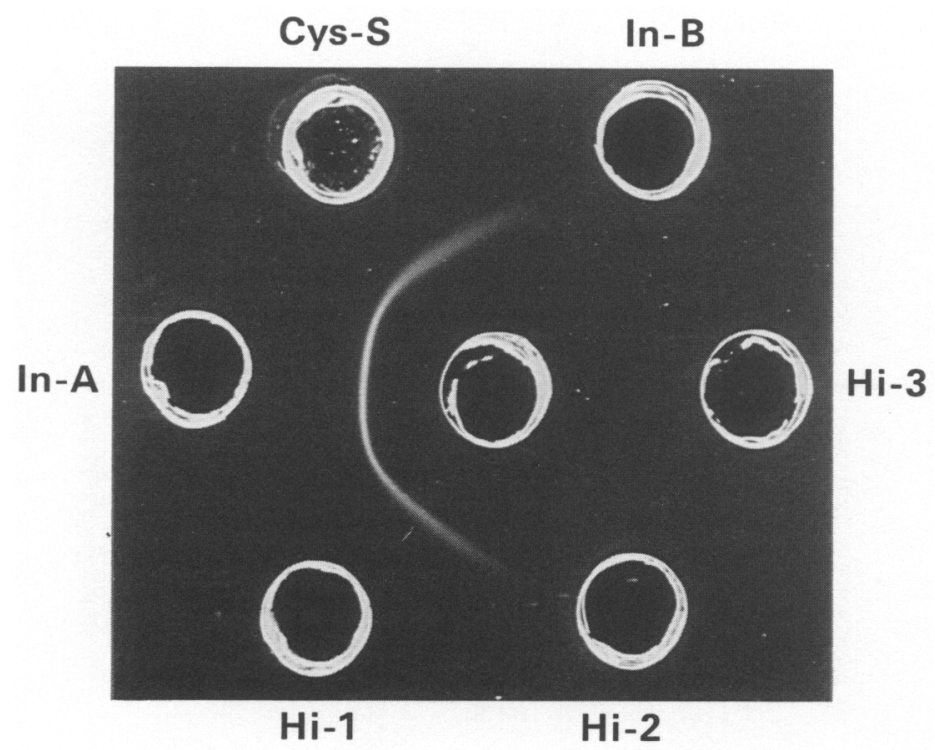

Fig. 2. Double immunodiffusion of cysteine proteinase inhibitors in human male sex gland, semen and saliva. Anti Cys-S (one of the cysteine proteinase inhibitors in human saliva) antibody was put in the middle well, $\mathrm{Hi}-\mathrm{l}, \mathrm{Hi}-2$ and $\mathrm{Hi}-3$ were inhibitors from the seminal vesicle and In-A and In-B were inhibitors in semen. The photograph was taken after incubation for $5 \mathrm{~h}$ at $37^{\circ} \mathrm{C}$ in a humid chamber.

molecular masses determined by the Sephadex G-100 gel filtration method were 90000 for Ri-1 and $\mathrm{Ri}-2$, and 11000 for $\mathrm{Ri}-3$ and $\mathrm{Ri}-4$. There was no reaction of $\mathrm{Ri}-1, \mathrm{Ri}-2, \mathrm{Ri}-3$ and $\mathrm{Ri}-4$ with antiserum against human Cys-S in an Ouchterlony double-immunodiffusion system.

\section{Discussion}

There have been several investigations on endogenous inhibitors of cysteine proteinases in human and rat livers (Green et al., 1984), spleens (Järvinen \& Rinne, 1982) and other organs (Lenney et al., 1979). Most of the inhibitors were present in multiple molecular forms like Hi-1-3 and Ri-1-4 in sex glands. They showed some differences in amino acid composition, sequence, isoelectric point and immunological reactivity (Barrett et al., 1984). These differences might reflect the differences in function of the inhibitors despite their similar inhibitory power against cysteine proteinases in vitro (Barrett et al., 1984).

The preliminary antigenicity investigation indicated that $\mathrm{Hi}-1$ and In-A had a common antigenicity to that of Cys-S in saliva. Both Hi- 1 and In-A inhibited ficin and cathepsin $\mathrm{H}$ equally, and had nearly the same isoelectric point. However, the molecular mass of $\mathrm{Hi}-1$ was much higher than that of In-A. Hi-3 in human seminal vesicle had the same isoelectric point and molecular mass as those of In-B in human semen. Hi-3 was not found in testis of prostate. Therefore, Hi-3 might be synthesized in the seminal vesicle or chemically modified in the seminal vesicle from an original substance.

The inhibitory power against trypsin was weaker than that against ficin in the homogenates of the three human sex glands. This tendency was in accordance with that observed in human semen (Minakata \& Asano, 1985). 


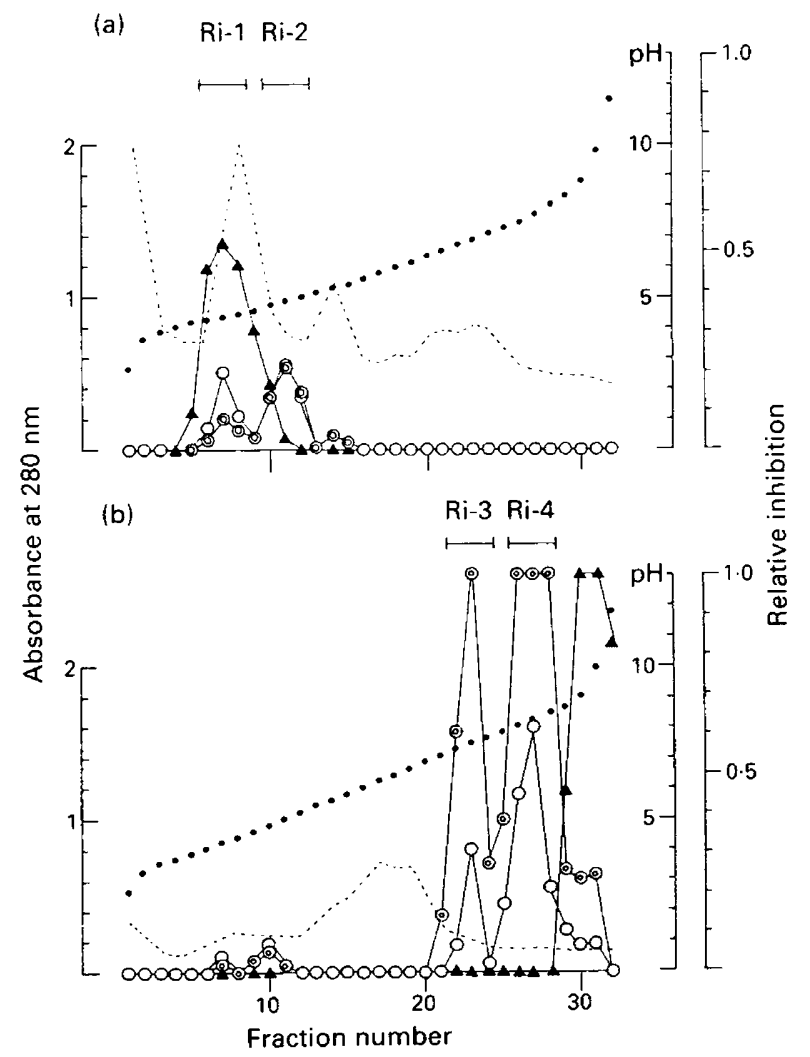

Fig. 3. Electrofocussing of proteinase inhibitors in (a) testicular and (b) seminal vesicle tissue in rats. The inhibitory activities of $0.15 \mathrm{ml}$ eluates were tested against $0.15 \mathrm{nmol}$ ficin $\left(\mathrm{O}_{-} \mathrm{O}\right)$, cathepsin $\mathbf{H}(\odot-\bigcirc)$ and trypsin $(\Delta-\Delta)$. $-\mathrm{pH}$ value; --- u.v. absorbance of the eluate.

In humans and rats, testis and prostate did not contain basic cysteine proteinase inhibitors, whereas the seminal vesicle contained basic inhibitors such as $\mathrm{Hi}-3, \mathrm{Ri}-3$ and $\mathrm{Ri}-4$. $\mathrm{Ri}-1$ and $\mathrm{Ri}-2$ in the rat had nearly the same isoelectric point, molecular mass, and specificity against cysteine proteinases as did $\mathrm{Hi}-1$ in human. $\mathrm{Ri}-3$ and $\mathrm{Ri}-4$ had nearly the same isoelectric point, molecular mass and specificity against cysteine proteinases as did $\mathrm{Hi}-3$.

\section{References}

Barrett, A.J. (1972) A new assay for cathepsin $B_{1}$ and other thiol proteinases. Analyt. Biochem. 47, 280-293.

Barrett, A.J., Davies, M.E. \& Grubb, A. (1984) The place of human $\gamma$-trace (cystatin $C$ ) amongst the cysteine proteinase inhibitors. Biochem. Biophys. Res. Commun. 120, 631-636.

Davidson, E. \& Poole, B. (1975) Fractionation of the rat liver enzymes that hydrolyze benzoyl-arginine2-naphthylamide. Biochim. Biophys. Acta 397, $437-442$.
Evans, H.M. \& Bishop, K.S. (1922) On the relations between fertility and nutrition. I. The ovulation rhythm in the rat on a standard nutritional regime. $J$. Metabol. Res. 1, 319-333.

Green, G.D.J., Kembhavi, A.A., Davies, E. \& Barrett, A.J. (1984) Cystatin-like cysteine proteinase inhibitors from human liver. Biochem. J. 218, 939-946.

Isemura, S., Saitoh, E. \& Sanada, K. (1984a) Isolation and amino acid sequence of SAP-1, an acidic protein of human whole saliva, and sequence homology with human $\gamma$-trace. J. Biochem. 96, 489-498. 
Isemura, S., Saitoh, E., Ito, S., Isemura, M. \& Sanada, K. (1984b) Cystatin $S:$ a cysteine proteinase inhibitor of human saliva. J. Biochem. 96, 1311-1314.

Järvinen, M. \& Rinne, A. (1982) Human spleen cysteinproteinase inhibitor. Purification, fractionation into isoelectric variants and some properties of the variants. Biochim. Biophys. Acta 708, 210-212.

Lenney, J.F., Tolan, J.R., Sugai, W.J. \& Lee, A.G. (1979) Thermostable endogenous inhibitors of cathepsins B and H. Eur. J. Biochem. 101, 153-161.

Matill, H.A. \& Conklin, R.E. (1920) The nutritive properties of milk, with special reference to reproduction in the albino rat. J. biol. Chem. 44, 137-158.

Minakata, K. \& Asano, M. (1984) New protein inhibitors of cysteine proteinases in human saliva and salivary glands. Hoppe-Seyler's Z. Physiol. Chem. 365, 399-403.

Minakata, K. \& Asano, M. (1985) Acidic cysteine proteinase inhibitors in seminal plasma. Biol. Chem. Hoppe-Seyler 366, 15-18.
Stambaugh, R., Brackett, B.G. \& Mastroianni, L. (1969) Inhibition of in vitro fertilization of rabbit ova by trypsin inhibitors. Biol. Reprod. 1, 223-227.

Sure, B. (1923-24) Dietary requirements for reproduction. II. The existence of a specific vitamin for reproduction. J. biol. Chem. 58, 693-709.

Tamai, M., Hanada, K., Adachi, T., Oguma, K., Kashiwagi, K., Omura, S. \& Ohzeki, M. (1981) Papain inhibitions by optically active E-64 analogs. J. Biochem. 90, 255-257.

Zaneveld, L.J.D., Robertson, R.J., Kessler, M. \& Williams, W.L. (1970) Inhibition of fertilization in vivo by pancreatic and seminal plasma trypsin inhibitors. J. Reprod. Fert. 25, 387-392.

Received 23 August 1986 